\title{
Bridging Cultural Differences through Established Cross-Border
}

\section{Economic Relations}

\author{
Christina Laspa ${ }^{1 *}$ \\ ${ }^{1}$ Independent Researcher, Ph.D, M.Sc., Athens, Greece \\ * Christina Laspa, E-mail: jepf@scholink.org
}

\begin{abstract}
Purpose: the paper aims to investigate if the countries that conduct cross border investments and trade are transferring their own culture to the host countries. Methodology: culture was represented by book collections' data selected by the digital library LibraryThing. In total 2,569 book-titles that represent the 50 top books of 52 country-groups have been used as the study's sample. Author's Nationality was set as the country of influence. Statistical analysis was employed to measure if the book collections of LT users were of foreigner-driven or homoethnic-driven authorship. Findings: the most industrialized countries and the best exporting countries were the best performers in culture transferring. Statistical significance with the amount of the books traded abroad was found to (i) the outward FDIs in millions of $\$$ ( $p=0.004)$, (ii) the stock of outward FDIs in millions of $\$(p<0.001)$, (iii) the outward FDIs as GDP percentage $(p=0.004)$, and $(v)$ the export volume index $(p=0.011)$. Regression analysis showed that outward FDIs in mil. $\$(p=0.016)$ and outward FDIs stock in mil. $\$(p<0.001)$ were significant predictors of a country's success to transfer its own cultural product abroad. Originality/value: this research is addressed to a tangible cultural output, books, issuing the objectiveness in measurements.
\end{abstract}

\section{Keywords}

culture economics, cultural differences, outward FDIs, exports, LibraryThing, book collections

\section{Introduction}

The way FDIs bridge or aggravate cultural difference between the investor and the host country by changing consumers' behavior in arts and literature so far is an uncharted field of research. Culture is not only manifested in labor abilities, communication skills, customs, traditions, and social behavior but also in civilization, heritage, and intellectual and artistic creations. Among these categories of culture, in this article we investigate intellectual creations which are embodied in books. Books are the final product of published literature and appertain also to the artistic creations. Consequently, book sales are a measure of demand and reflect a cultural outcome. The demand on specific books and authors is formed by reading preferences. Literature upon reading preferences is limited. Nevertheless data regarding yearly sales (amount, revenues and international trade), can be traced on the internet for a few countries but the distinction of foreign and domestic authorship is not directly detectable. Closely 
related to this fact, previous research on foreign authorship is oriented to the library science and specifically to the foreign language collections of academic libraries (Astroff, 2001).

While reading as part of the educational goals and achievement at a national level is monitored for decades (NAEP, 2013), reading trends for pleasure were scarcely investigated to adults. Indeed academic research explored mostly reading habits of school's children (OECD, 2002; Clark \& Foster, 2005; Sainsbury \& Schagen, 2004; Clark \& Rumbold, 2006).

In this framework, mapping reading preferences in a country or worldwide it is so far a context of enormous potentiality given the distinct disciplines and research aims that may be involved. Each discipline may include several indexes of success related to several variables and timeseries variation. For instance, a Publishing House is interested to measure year per year the amount of issued books totally or by category, the book industry's revenues, the book imports/exports, the best selling books and other data for business and marketing purposes. A university or a governmental entity may be interested about the diffusion of reading scientific books in specific age or ethnic groups in order to develop technology oriented educational programs.

Some other disciplines may not be so apparent such as the political and economic science. In fact, investigating the book markets of domestic versus the foreign authorship in a country it is revealed information about the cultural orientation of a given population generated by reading preferences. Anthologizing the authorship rates in a given period may produce scientific knowledge in explaining a country's particular circumstances, historical singularities, economic and political influences (colonialism, enforcement, international trade and international relations). Globalization, geographical vicinity close relationships between countries and immigration are also explanatory factors that can be issued in a related case-study research. Authors' mastery based on artistic excellence is not excluded given that classical literature is located to several countries during centuries.

In the era of globalization the channels of accessing books of the world are even easier for readers (i.e., book consumers). This fact makes more intriguing the challenge to search about what nationality the authors of the most preferred books worldwide have. This information may answer which country is successful in the global economic arena while more particulars can be discovered taking into account competitiveness or greater ability regarding cultural, linguistic, educational, entrepreneurship and other factors. To our knowledge so far there is not much information about the demographics of the most popular authors of the world, such as the sex, the age, the nationality, the marital status, the economic status, or even the health status. The quantification of particular characteristics of authors applies to the economic and social studies. Specifically, the nationality of an author reflects a certain culture, resulted by its proper ethnic and religious influence during his/her life. When the work (book) of an author is exported it is an indication of a possible diffusion of his/her culture to the cultures of other countries. In this context, a massive wave of exported culture implies the ability of a country to establish invisible power and persuasiveness to foreign ethnicities. The argument of cultural relations and new public diplomacy emphasize the distinctive quality on "engaging with foreign Published by SCHOLINK INC. 
audiences”...“mutuality”...“stable relationships”... and "building trust” (Melissen, 2005).

The exportation of books is linked to the international trade therefore it is important to trace the driving force(s) that form the related aggregate supply and demand. In other words, locating the factors that influence world readers to develop foreign authors' book collections, unfolds the inquiry of who, why, and how a country outcompete others in exporting books and diffuse its cultural status quo.

\section{Method}

\subsection{Literature Review}

It is a common belief in the economic studies that the international trade and FDIs attractiveness lead economies to a GDP development and a higher standard of living. The interactive relation of FDIs, exports and growth was evidenced by Hsiao and Hsiao (2006) and findings in the literature stated the positive impact of FDIs to the host economy by creating new job positions and technology transferring (Xu, 2000). According to Alfaro et al. (2010), the dynamic process of absorbing FDIs advantages is subject to an economy's capacity to take benefit given that local factors may reduce the strength of FDIs externalities. Moreover, an increased international trade and FDI flow has frequently indirect effects by improving the relations and alliances of the countries involved. Significant gain in terms of culture convergence from business conducted across national borders may be disregarded among diverse nations and cultures. Empirical results showed that cultural differences result as barriers or drivers to asset trade (Guiso, Sapienza, \& Zingales, 2009; Heuchemer \& Sander, 2007). On the other hand, Huberman (2001) presented numerous examples of familiarity as the factor that affects investment choices. He demonstrated that the tendency to invest in the familiar is resulted by the perception of risk and return. Tesar and Werner (1995) anticipate that cross-borders investment decisions are motivated by geographic proximity but it is not mentioned if this reflects cultural proximity as well.

Cultural influences generated by FDIs were investigated by several researchers. For instance, it is argued that the existing culture values of a country affect its attractiveness as a destination for business practices and FDIs by foreign firms (Hofstede, 1991, 2001; Bhardwaj, Arjun, \& Beamish, 2007). Previous research on the topic was oriented on the cultural determinants of FDI flows in order to detect foreign firms' preferences for a particular country. Cultural convergences/divergences were used as explanatory variables producing strong criticism due to the findings discrepancy and measurement conceptualization (Loree \& Guisinger, 1995; Jones \& Teegen, 2001; Shenkar, 2001).

On the other side the work of Lu, Qiangbing and Yali (2010), avoid measurement distortions approaching the cultural values as people's actions. Specifically they examined if there are changes in culture values generated by the FDIs inflows in China. Results showed significant effects on the degree of future orientation, performance orientation and in group collectivism produced by FDIs.

Whether a nation's culture affects FDIs attractiveness or the opposite still remains a prolific field to research for. So far, research has confronted culture and FDIs as an extended substratum of concepts in

Published by SCHOLINK INC. 
doing business. In other words culture was addressed as a notion of gap that potentially leads to hidden cost resulted by a foreign's firm location misjudged choice.

To our knowledge there is no research about a narrowed type of culture such as the cultural products consumed in the host country. In respect to these research possibilities the present article attempted to contribute empirical findings and results to the question as to what way FDIs and exports influence reading preferences and subsequently diffuse culture in the host countries.

Reading preferences were quantified by the book industry. The availability of digital libraries and the online resources of book collections give prominence to a research tool for data detection. The LibraryThing (LT) is possibly the largest website for cataloguing and organizing books worldwide. LT as a system supports catalogued books by over 50 countries. Consequently, country-groups were established as communities in the link "Languages". Additionally, LT creates a user friendly environment for user-groups due to the interface operation. Scholars and the Scottish CILT Library judged LT as the most appropriate source of cataloguing compared to others (such as Gurulib and Shelfari) in order to conduct academic research. The advantages of LT are substantial due to the higher volume of books that can be catalogued, the lack of advertisements, the use of different languages and the data originated by a great amount of book catalogues. Moreover, LT provides a frame of search (Catalogue search box) in the Scottish CILT Library's site by which users can directly search for book catalogues (Hvass, 2008).

The usefulness of the study lies on the assumption that if in a country-group the foreign authors are in a greater number compared to the domestic authors there must be a reason. In this framework, the overall objective of the research was to approach recent reading behavior through the 50 most popular books that appeared in LT. The research addressed the following broad points:

(1) To examine if the book collections of LT users are by homoethnic-driven authorship or by foreigner-driven authorship.

(2) To view which country's literature influences other countries' reading preferences.

(3) To investigate if the factor of influence is based on international economic relations among countries and specifically on international trade by examining whether or not the FDIs and exports of goods and services have an impact to literature and culture.

\subsubsection{The Digital Library LibraryThing}

With the emergence of the Web 2.0 technology the internet users gained a superior involvement in web applications (DiNucci, 1999). The Web 2.0 is the second generation of the World Wide Web and makes possible an intensive users' participation through complicated and personalized operations and synergies. For instance, sites of wikis kind, allow to the users the creation and processing of their content. Also provide extra possibilities such as chatting and text uploading by many users but defer in respect of their regulations, processes and aims. Other paradigms are the blogs, i.e., spaces of social networks.

LibraryThing is a digital library, based on the Web 2.0 technology. Its content is developed by its users Published by SCHOLINK INC. 
and it is practically a social cataloguing and a social networking site for book readers and collectors. As a system promotes a collaborative management in literature annotations and provides online spaces to its users for personal libraries and book cataloguing.

LT's architecture is developed in three levels, is managed by the users and reflects the philosophy of the system Functional Requirements of Bibliographic Records (FRBR) initiative, which is developed by the International Federation of Library Associations (IFLA) and Institutions (Denton, 2011; O’Neill, 2007).

Data uploaded by the users on the LT site become public to other users (Robinson, 2008). Under this view, LT application via the Web 2.0 not only provides an infrastructure of personal book collection in a form of a library cataloguing but also creates structures of interactive communication through the tag use and book reviews generated by the users.

LibraryThing is a characteristic example of user-centered qualities of Web 2.0. Tim O’Reilly (2007) described this as a collective intelligence given that non-professional LT users may operate as skilled librarians in a massive scale. Watson (2008) argues that this massiveness attributes a character of "attack" against the experts [professional librarians]. Moreover, Worrall (2010) deems that digital libraries must improve their support to social interaction by establishing communities about them in order to amalgamate social groups and communities. In his research on communities' establishment in LT and in digital libraries, he featured significant practices regarding improvements and support on their social content.

Research potentiality of LT was reported by other authors due to LT's applications and its possibilities to operate as a social tagging system for future retrieve of digital objects such as book titles, libraries collection and book catalogues (Spiteri, 2010; Kroski, 2007). So far the areas of research were oriented to the field of Library Science and its digital applications such as data organizing and retrieve or even taxonomy automations. For instance, Heymann, Koutrica and Garcia-Molina (2008) concluded that the social bookmarking, i.e., a taxonomy system for bookmarks, provides search-data unavailable though other sources though may present weaknesses in volume and tags appropriation.

Owing to the close interrelatedness of literature and culture, LT is a source of cultural evidence. Therefore, as the business is becoming increasingly international, LT unfolds its role to the discipline of cultural economics. To illustrate this point, this study explores the practical contributions that the international business can make to culture.

\subsection{Data \& Methodology}

The research was based to the digital library of Librarything which is an online resource of book collections. First, from the main menu and the overview link "Zeitgeist", country-groups were searched from the auxiliary link "Languages”. The new page "Zeitgeist by Languages” presents 54 countries or language related groups and statistics are given upon the number of members, the books catalogued, the tags, the reviews and the subgroups of communication. These country-related groups cover mostly European countries and New Europe's countries (26 linked to the principal countries and four 
additional ethnic or linguistically diversified minorities). There are also three former Soviet Republics including Russia, eleven placed in Asia and Meddle East including China, India and Indonesia, and one in Latin America. The African Continent is represented by only one data entry and the remaining ethnic groups are mostly linguistically diversified entries (see for example "Chinese traditional” and "Chinese simplified") or unclassified (see "Piratical" and "Esperanto"). Data were retrieved on the $30^{\text {th }}$ June 2013. The population of the above related countries ( 4.35 billion of people) represents $60 \%$ of world's population (7.26 billion of people) but the members of LT "Languages" amount only 157,080. This sample represents a small proportion of these 54 countries' population and world's population ( $0.0036 \%$ and $0.0022 \%$ respectively) but it is seriously committed to read, collect, review and tag books. In $30^{\text {th }}$ June 2013 in LT "Languages" link there were 5,705,607 books catalogued, 7,782,188 tags and 155,551 reviews. Therefore the sample reflects ethnic communities formed by the elite of sophisticated persons.

In order to make valuable conclusions about the cultural influence of a country to another country the study set criteria of groups' exclusion. The research excluded only two groups (the known technical language "Esperanto" and "Piratical") because are not closely referred to an independed state or to an ethnic minority within an independed state. In fact, groups related to ethnic minorities with linguistic differences of specific nature were explored as well. Therefore, autonomous communities such as the Catalan and the Basque groups were included in the sample as presented in the LT. Moreover, groups referred to administrative districts of a country (such as Welsh), to an entire Continent (such as Afrikaans), and to modern/traditional language discrimination, were also included. Therefore, the final country and language groups included in the study were 52. For each group the top 50 book-titles are featured in the LT which represent the most widely-read and catalogued books placed by the higher to the lower rank. In other words, a country's reading preferences can be traced by LT searching the 50 most successful books. All book-titles were searched about the authors' Nationality and the original language of writing. These two variables were statistically recorded and set as the factors of cultural influence. In cases where a language is used in more than one country (English, Spanish, Portuguese) the authors' Nationality and birthplace were considered as the country of influence.

The study followed four steps. First it was aiming to investigate the reading preferences of the country-groups extrapolating the frequency of domestic authors compared to foreign authors. Quantitative variables were presented with absolute and relative frequencies. If the percentage of foreign authors were found greater, then the cultural influence from other countries was assumed. Second, the range of foreign authorships was recorded in order to illustrate any multicultural influences or the relative weight of a country to another. If the majority of foreign authorships were found to be from a specific country then an evidence of influence from a particular country was also assumed. On the opposite, if foreign authorships were found to belong to several countries then an evidence of multicultural influence was assumed. Third, a rank of countries which were found to be in the lists of the 50 book-titles as foreign authorships was developed by the number of book-titles frequencies in Published by SCHOLINK INC. 
each country group. In this step it was evaluated which countries are the best-performers in exporting their own culture worldwide. Four, in order to uncover the factors that are the driving forces of culture exportation, seven indicators of international economic relations were used: (i) the outward FDIs in millions of \$, (ii) the stock of outward FDIs in millions of \$ which covers the period 1980-2012, (iii) the outward FDIs as GDP percentage, (iv) the outward FDIs as Gross Fixed Capital Formation (GFCF) percentage, (v) the exports as GDP percentage, (vi) the export value index, and (vii) the export volume index. FDIs data were selected by the statistical database of United Nation Conference on Trade and Development (UNCTAD) and exports data were retrieved by the World Bank Data link. All data are referred to the year 2012. At this step, data were modeled using stepwise linear regression analysis. The depended variable was the volume of book-titles attributed as foreign authorships by country of origin which reflects the aggregate demand for books sold abroad by exporter country. Regression coefficients $(\beta)$ with Standard Errors (SE) were computed from the results of the linear regression analysis. All p-values reported are two-tailed and statistical significance was set at 0.05 . Based on the hypothesis that a cultural impact occurs when previous cross-border economic relations exist as expressed by each FDI and export indicators, it was tested whether or not cultural difference can be smoother after cross-border economic relations taking place. Statistical analysis was conducted using SPSS statistical software (version 17.0).

\section{Result}

\subsection{Foreign versus Domestic Literature \& Range of Multicultural Effect}

The link "Languages" contains 54 ethnic or linguistic groups which have catalogued 5,705,607 books. Two groups were excluded due to their irrelevance to any ethnicity or country (see Pirates and Esperanto). The remaining catalogued books amount 5,674,913 titles. The link automatically presents the 50 top book-titles by ethnic/linguistic group followed by the number of users that have catalogued it. These 50 top books represent 2,569 book-titles which have been used as the final sample of the study. The 50 top books of each country group were searched according to the author's Nationality and the original text language. Clicking on each book-title it can be traced information upon the author and further clicking leads to his/her demographic data (name legal, canonical and other names), gender, dates of birth and burial, place of birth and Nationality (native or by naturalization), education, places of residence, occupations, relations, i.e., marital status, awards and honors, organizations, agents and a short biography. The authors of a foreign Nationality were calculated in order to view the extent of reading preferences among domestic and foreign literature. Most of the books of the sample belong to the modern literature followed by the classical masterpieces while fewer are categorized to business, health, kids' literature, science fiction, ancient Greece/Roman Empire, bilingual dictionaries, religious themes and technical guides.

For instance in the Spanish group the three top book titles in the 30th June 2013 were: 
(a) Cien años de soledad (729), which is authored by Gabriel Garcia Marquez, and his birthplace and Nationality is Colombian. The original language of the work was Spanish.

(b) La sombra del viento (471), which is authored by Carlos Ruiz Zafón, and his birthplace and Nationality is Spanish. The original language of the work was Spanish.

(c) Los pilares de la Tierra (434), which is authored by Ken Follett, and his birthplace is the United Kingdom and his Nationality is British.

The research is based on a sample of three world's Continents. The first step of the study was to measure the consumption of foreign and domestic literature. Findings showed that consumers preference on domestic authors was very low (18.68\%). The number of foreign authorships was 81.16\% and about $0.2 \%$ was attributed to anonymous authors. Findings show that every five books only one is authored by a domestic writer which reflects a meaningful effect of foreign cultures across the world. Descriptive statistics show that the mean for domestic authors is 9.48 and for the foreign authors is 40.52 . The Std. Deviation is 8.835 for both cases. Figure 1 illustrates the boxes representing the spread and centers of books by domestic and foreign authorship and Figure 2 shows the respective distribution.
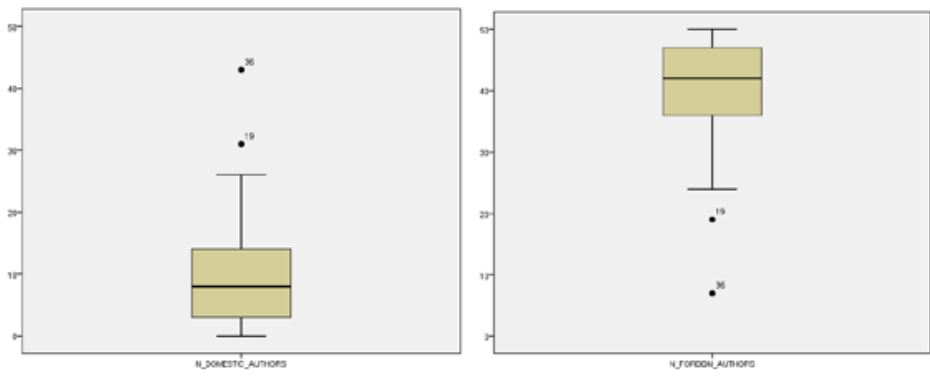

Figure 1. Box Plots of Books by Domestic and Foreign Authorship
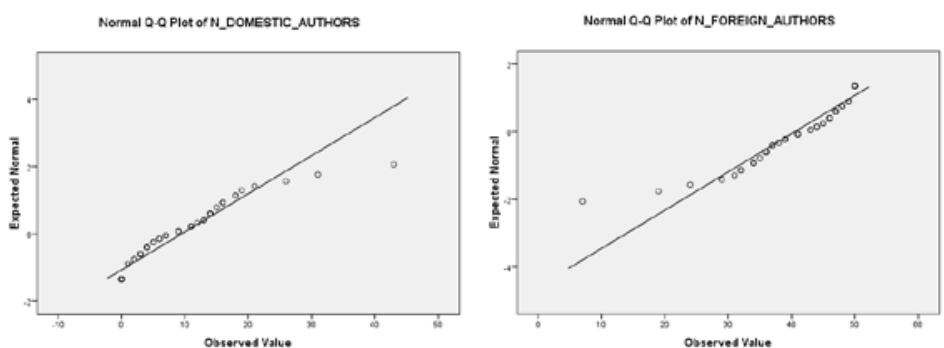

Figure 2. Distribution Plots of Books by Domestic and Foreign Authorship

Results denote that there is differency among ethnic-groups upon foreign authors' collections. All of the 52 country-groups had book collection with foreign authors (min 14\% and max 100\%). Isolating the foreign collection in each group it is possible to get information about the variety of foreign authorships Published by SCHOLINK INC. 
by country of origine. Results denote that the country-groups collect foreign books by at least three different countries and at the maximum nineteen different countries. As an average the country-groups collect books by 11 different countries (mode $=10$ foreign countries).

Eight country-groups consumed only foreign literature (see Table 1). It is noteworthy that six of these groups are referred to transition economies (i.e., countries in the process of changing from a centrally planned economy to a market economy). The remaining two groups are referred to the Republic of Korea and Africa. The lowest percentage of collecting works of domestic authors was noticed to the Bulgarian and Slovenian groups (2\%), followed by the Greek and Urdu (Pakistan) groups (4\%). Domestic authorships lower than 10\% was found to Spanish, Czechian, Lithuanian, Latvian, Persian, Portuguese, Chinese Traditional and Yiddish groups. A little higher score were found to groups related to the North and Central Europe groups. For instance the German and the Danish groups had a score of $22 \%$, followed by the Polish, the French and the Dutch with 24\%, 32\% and 36\% respectively. The five Scandinavian country-groups present a mean score of 22.4\% (minimum 14\% and maximum 32\%) of preference on domestic authors. The three groups related to the autonomous communities of Spain (Catalan (32\%), Basque (28\%) and Galician (28\%)) presented about five times higher scores of domestic authorships than the Spanish group (6\%). Significant rates of domestic culture preferences were found in the Hindi group (38\%) and the Arabic group (36\%). Over 50\% was found only to three groups: the administrative district of UK Welsh group (86\%), the Chinese Simplified group (52\%) and the Japanese group (62\%). It is notable that UK, China and Japan are great exporters of goods and services during the last years. In fact China's exports are estimated about $\$ 2.300$ trillion which is equivalent of 24\% of GDP (average for the period 2009-2012). Japan's exports performance reach more than $\$ 710.5$ billion which for the same period corresponds to $14.5 \%$ of GDP. Finally UK's exports amount to $\$ 503.4$ billion and as an average is relative to the $29.2 \%$ of GDP.

Table 1. Domestic and Foreign Book-Titles per Country-Group

\begin{tabular}{lllllll}
\hline Country group & $\begin{array}{l}\text { Book-titles } \\
\text { of domestic } \\
\text { authors (N) }\end{array}$ & $\%$ & $\begin{array}{l}\text { Book-titles } \\
\text { of foreign } \\
\text { authors (N) }\end{array}$ & $\begin{array}{l}\text { Variety of foreign } \\
\text { authorships (N) of } \\
\text { countries }\end{array}$ \\
\hline 1 & Spanish & 3 & $6 \%$ & 47 & $94 \%$ & 15 \\
2 & Dutch & 18 & $36 \%$ & 32 & $64 \%$ & 13 \\
3 & German & 11 & $22 \%$ & 39 & $78 \%$ & 10 \\
4 & French & 16 & $32 \%$ & 34 & $68 \%$ & 10 \\
5 & Italian & 14 & $28 \%$ & 36 & $72 \%$ & 12 \\
6 & Portuguese_Brazil & 5 & $10 \%$ & 45 & $90 \%$ & 12 \\
7 & Portuguese_Portugal & 14 & $28 \%$ & 36 & $72 \%$ & 14 \\
8 & Swedish & 15 & $30 \%$ & 35 & $70 \%$ & 10 \\
\hline
\end{tabular}




\begin{tabular}{|c|c|c|c|c|c|c|}
\hline 9 & Danish & 11 & $22 \%$ & 39 & $78 \%$ & 10 \\
\hline 10 & Finnish & 7 & $14 \%$ & 43 & $86 \%$ & 11 \\
\hline 11 & Norwegian & 16 & $32 \%$ & 34 & $68 \%$ & 14 \\
\hline 12 & Polish & 12 & $24 \%$ & 38 & $76 \%$ & 10 \\
\hline 13 & Greek & 2 & $4 \%$ & 48 & $96 \%$ & 13 \\
\hline 14 & Hungarian & 9 & $18 \%$ & 41 & $82 \%$ & 10 \\
\hline 15 & Catalan & 16 & $32 \%$ & 34 & $68 \%$ & 13 \\
\hline 16 & Turkish & 13 & $26 \%$ & 37 & $74 \%$ & 9 \\
\hline 17 & Russian & 14 & $28 \%$ & 36 & $72 \%$ & 12 \\
\hline 18 & Czech & 4 & $8 \%$ & 46 & $92 \%$ & 13 \\
\hline 19 & Japanese & 31 & $62 \%$ & 19 & $38 \%$ & 7 \\
\hline 20 & Lithuanian & 3 & $6 \%$ & 47 & $94 \%$ & 12 \\
\hline 21 & Albanian & 0 & $0 \%$ & 50 & $100 \%$ & 13 \\
\hline 22 & Latin & 9 & $18 \%$ & 41 & $82 \%$ & 9 \\
\hline 23 & Bulgarian & 1 & $2 \%$ & 49 & $98 \%$ & 6 \\
\hline 24 & Romanian & 6 & $12 \%$ & 44 & $88 \%$ & 11 \\
\hline 25 & Chinese_Traditional & 4 & $8 \%$ & 46 & $92 \%$ & 7 \\
\hline 26 & Croatian & 0 & $0 \%$ & 50 & $100 \%$ & 15 \\
\hline 27 & Slovak & 0 & $0 \%$ & 50 & $100 \%$ & 7 \\
\hline 28 & Chinese_Simplified & 26 & $52 \%$ & 24 & $48 \%$ & 8 \\
\hline 29 & Estonian & 11 & $22 \%$ & 39 & $78 \%$ & 11 \\
\hline 30 & Hindi & 19 & $38 \%$ & 31 & $62 \%$ & 7 \\
\hline 31 & Latvian & 3 & $6 \%$ & 47 & $94 \%$ & 12 \\
\hline 32 & Arabic & 18 & $36 \%$ & 32 & $64 \%$ & 10 \\
\hline 33 & Basque & 14 & $28 \%$ & 36 & $72 \%$ & 12 \\
\hline 34 & Portuguese_B\&P & 4 & $8 \%$ & 46 & $92 \%$ & 12 \\
\hline 35 & Icelandic & 7 & $14 \%$ & 43 & $86 \%$ & 11 \\
\hline 36 & Welsh & 43 & $86 \%$ & 7 & $14 \%$ & 3 \\
\hline 37 & Hebrew & 13 & $26 \%$ & 37 & $74 \%$ & 14 \\
\hline 38 & Irish & 21 & $42 \%$ & 29 & $58 \%$ & 3 \\
\hline 39 & Serbian & 9 & $18 \%$ & 41 & $82 \%$ & 15 \\
\hline 40 & Korean & 0 & $0 \%$ & 50 & $100 \%$ & 10 \\
\hline 41 & Persian & 4 & $8 \%$ & 46 & $92 \%$ & 10 \\
\hline 42 & Africaans & 0 & $0 \%$ & 50 & $100 \%$ & 9 \\
\hline 43 & Tagalog & 5 & $10 \%$ & 45 & $90 \%$ & 11 \\
\hline 44 & Armenian & 0 & $0 \%$ & 50 & $100 \%$ & 8 \\
\hline
\end{tabular}




\begin{tabular}{lllllll}
\hline 45 & Indonesian & 6 & $12 \%$ & 44 & $88 \%$ & 9 \\
46 & Slovenian & 1 & $2 \%$ & 49 & $98 \%$ & 10 \\
47 & Georgian & 0 & $0 \%$ & 50 & $100 \%$ & 12 \\
48 & Urdu (Pakistan) & 2 & $4 \%$ & 48 & $96 \%$ & 4 \\
49 & [FYR]Macedonian & 0 & $0 \%$ & 50 & $100 \%$ & 12 \\
50 & Galician & 14 & $28 \%$ & 36 & $72 \%$ & 10 \\
51 & Yiddish & 3 & $6 \%$ & 47 & $94 \%$ & 19 \\
52 & Chinese & 3 & $6 \%$ & 47 & $94 \%$ & 6 \\
\hline
\end{tabular}

Source: Elaborated data from the LibraryThing Zeitgeist Languages link.

\subsection{Best Performer Countries in Exporting Culture}

The following step of the study was to indicate the best performers on exporting their books and consequently their culture. 45 countries appeared as having exported their own culture abroad through domestic authorships translations to the host countries' language. UK is the leader of exporting culture with 756 entries of UK authors that represent the $29.43 \%$ of the sample. Authors born in the USA have the second higher score of foreigner reading preferences (25.65\%). These figures denote that the book collectors on LT are strongly committed to a certain linguistic homogeneity, i.e., the English language. Taking into account the other countries that use the English such as the Ireland ( $N=25,0.97 \%)$, Canada $(\mathrm{N}=20,0.78 \%)$, Australia $(\mathrm{N}=17,0.66 \%)$ and $\mathrm{N}$. Zealand $(\mathrm{N}=1,0.04 \%)$ it is obvious that the percentage of books written originally in the English language represent the $57.53 \%$ of the total sample which corresponds to a market share of $70.9 \%$. This means that the book exportations are dominated by English-speakers authors. In order to investigate the reason of UKs and USAs lead, we assumed that the success of their creative economy is driven by their FDIs abroad which produce a dynamic trend of cultural products endorsement by the host countries. France is classified as third with less than $3 \%$ of the total book-titles. Results by country are presented in the Table 2 .

Table 2. Exported Culture as Percentage of Foreign Authors by Country of Origin

\begin{tabular}{lllll}
\hline Rank & Exporter country & N of book-titles abroad & \% of total book-titles & \% Market share \\
\hline 1 & UK & 756 & $29.43 \%$ & $36.26 \%$ \\
2 & USA & 659 & $25.65 \%$ & $31.61 \%$ \\
3 & FRANCE & 76 & $2.96 \%$ & $3.65 \%$ \\
4 & RUSSIA & 55 & $2.14 \%$ & $2.64 \%$ \\
5 & SWEDEN & 53 & $2.06 \%$ & $2.54 \%$ \\
6 & GERMANY & 52 & $2.02 \%$ & $2.49 \%$ \\
7 & ITALY & 44 & $1.71 \%$ & $2.11 \%$ \\
8 & BRAZIL & 41 & $1.60 \%$ & $1.97 \%$ \\
\hline
\end{tabular}




\begin{tabular}{|c|c|c|c|c|}
\hline 9 & COLOMBIA & 34 & $1.32 \%$ & $1.63 \%$ \\
\hline 10 & CZECH REP. & 32 & $1.25 \%$ & $1.53 \%$ \\
\hline 11 & JAPAN & 31 & $1.21 \%$ & $1.49 \%$ \\
\hline 12 & IRELAND & 25 & $0.97 \%$ & $1.20 \%$ \\
\hline 13 & SPAIN & 23 & $0.90 \%$ & $1.10 \%$ \\
\hline 14 & AFGANISTAN & 24 & $0.93 \%$ & $1.15 \%$ \\
\hline 15 & CANADA & 20 & $0.78 \%$ & $0.96 \%$ \\
\hline 16 & AUSTRALIA & 17 & $0.66 \%$ & $0.82 \%$ \\
\hline 17 & NORWAY & 15 & $0.58 \%$ & $0.72 \%$ \\
\hline 18 & SWITZERLAND & 13 & $0.51 \%$ & $0.62 \%$ \\
\hline 19 & POLAND & 13 & $0.51 \%$ & $0.62 \%$ \\
\hline 20 & UKRAINE & 12 & $0.47 \%$ & $0.58 \%$ \\
\hline 21 & GREECE & 12 & $0.47 \%$ & $0.58 \%$ \\
\hline 22 & BELGIUM & 10 & $0.39 \%$ & $0.48 \%$ \\
\hline 23 & CHILE & 9 & $0.35 \%$ & $0.43 \%$ \\
\hline 24 & NETHERLANDS & 9 & $0.35 \%$ & $0.43 \%$ \\
\hline 25 & DENMARK & 8 & $0.31 \%$ & $0.38 \%$ \\
\hline 26 & CHINA & 5 & $0.19 \%$ & $0.24 \%$ \\
\hline 27 & ALGERIA & 4 & $0.16 \%$ & $0.19 \%$ \\
\hline 28 & INDIA & 4 & $0.16 \%$ & $0.19 \%$ \\
\hline 29 & BOSNIA & 4 & $0.16 \%$ & $0.19 \%$ \\
\hline 30 & AUSTRIA & 4 & $0.16 \%$ & $0.19 \%$ \\
\hline 31 & S. AFRICA & 3 & $0.12 \%$ & $0.14 \%$ \\
\hline 32 & FINLAND & 2 & $0.08 \%$ & $0.10 \%$ \\
\hline 33 & HUNGARY & 2 & $0.08 \%$ & $0.10 \%$ \\
\hline 34 & LEBANON & 2 & $0.08 \%$ & $0.10 \%$ \\
\hline 35 & ICELAND & 2 & $0.08 \%$ & $0.10 \%$ \\
\hline 36 & ARMENIA & 1 & $0.04 \%$ & $0.05 \%$ \\
\hline 37 & SRI LANKA & 1 & $0.04 \%$ & $0.05 \%$ \\
\hline 38 & KYRGYZSTAN & 1 & $0.04 \%$ & $0.05 \%$ \\
\hline 39 & PHILIPPINES & 1 & $0.04 \%$ & $0.05 \%$ \\
\hline 40 & SERBIA & 1 & $0.04 \%$ & $0.05 \%$ \\
\hline 41 & CROATIA & 1 & $0.04 \%$ & $0.05 \%$ \\
\hline 42 & ARGENTINA & 1 & $0.04 \%$ & $0.05 \%$ \\
\hline 43 & N. ZEALAND & 1 & $0.04 \%$ & $0.05 \%$ \\
\hline 44 & TURKEY & 1 & $0.04 \%$ & $0.05 \%$ \\
\hline
\end{tabular}




\begin{tabular}{lllll}
\hline 45 & S. KOREA & 1 & $0.04 \%$ & $0.05 \%$ \\
& TOTAL & 2085 & $100.00 \%$ & $100.00 \%$
\end{tabular}

Source: Elaborated data from the LibraryThing Zeitgeist Languages link.

\subsection{Statistical Tests}

In the final step, data regarding outward FDIs and export rates of goods and services to the countries under study will give a picture of a direct or indirect cultural influence reflected in reading preferences. Results were employed under statistical tests in order to reveal any relation to FDIs and exports to the reading preferences of each country groups. Table 3 presents the correlations employed. Statistical significance was found in four variables. Specifically, outward FDIs is a strong factor of affecting the culture of the host countries given that the p values of outward FDIs in mil. \$ and expressed as GDP\% were 0.004. Additionally, a stronger significance was found to the variable of outward FDIs stock in millions of $\$(p<0.001)$ and the export volume index $(\mathrm{p}=0.011)$. Table 3 shows also the statistical significance of outward FDIs and exports' indexes. For instance, the export volume index is related to the outward FDIs stock ( $\mathrm{p}=0.027)$, outward FDIs as GDP\% $(\mathrm{p}=0.005)$ and export value index $(\mathrm{p}<0.001)$. Export as GDP\% is related to outward FDIs as GDP\% ( $\mathrm{p}=0.001)$ and outward FDIs as GFCF\% ( $=0.005)$.

Table 3. Statistical Tests

\begin{tabular}{|c|c|c|c|c|c|c|c|c|c|c|}
\hline \multicolumn{11}{|c|}{ Correlations $^{\mathrm{a}}$} \\
\hline \multirow{11}{*}{$\begin{array}{l}\text { Spearman's } \\
\text { rho }\end{array}$} & & & \multirow[b]{2}{*}{$\begin{array}{l}\text { SUM_BO } \\
\text { OK } \\
\text { AUTHOR }\end{array}$} & \multicolumn{4}{|c|}{ FDI OUTWARD 2012} & \multicolumn{3}{|c|}{ EXPORTS 2012} \\
\hline & & & & MIL.\$ & $\begin{array}{l}\text { STOCK } \\
\text { MIL.\$ }\end{array}$ & GDP\% & $\begin{array}{l}\text { AS } \\
\text { GFCF\% }\end{array}$ & $\begin{array}{l}\text { AS } \\
\text { GDP\% }\end{array}$ & $\begin{array}{l}\text { INDEX } \\
2000=100\end{array}$ & $\begin{array}{l}\text { INDEX } \\
2000=100\end{array}$ \\
\hline & SUM_BOOK & Correlation & 1.000 & $.422^{* *}$ & $.662^{* *}$ & $.417^{* *}$ & .257 & -.137 & -.238 & $-.375^{*}$ \\
\hline & AUTHOR & Coefficient & & & & & & & & \\
\hline & & Sig. (2-tailed) & . & .004 & .000 & .004 & .088 & .369 & .116 & .011 \\
\hline & FDI & Correlation & $.422^{* *}$ & 1.000 & $.724^{* *}$ & $.467^{* *}$ & $.797^{* *}$ & .090 & $-.329^{*}$ & -.224 \\
\hline & OUTWARD_ & Coefficient & & & & & & & & \\
\hline & MIL.\$ & Sig. (2-tailed) & .004 & . & .000 & .001 & .000 & .556 & .027 & .139 \\
\hline & FDI & Correlation & $.662^{* *}$ & $.724^{* *}$ & 1.000 & $.715^{* *}$ & $.476^{* *}$ & .004 & $-.440^{* *}$ & $-.331^{*}$ \\
\hline & OUTWARD & Coefficient & & & & & & & & \\
\hline & STOCK_MIL & Sig. (2-tailed) & .000 & .000 & . & .000 & .001 & .978 & .003 & .027 \\
\hline
\end{tabular}




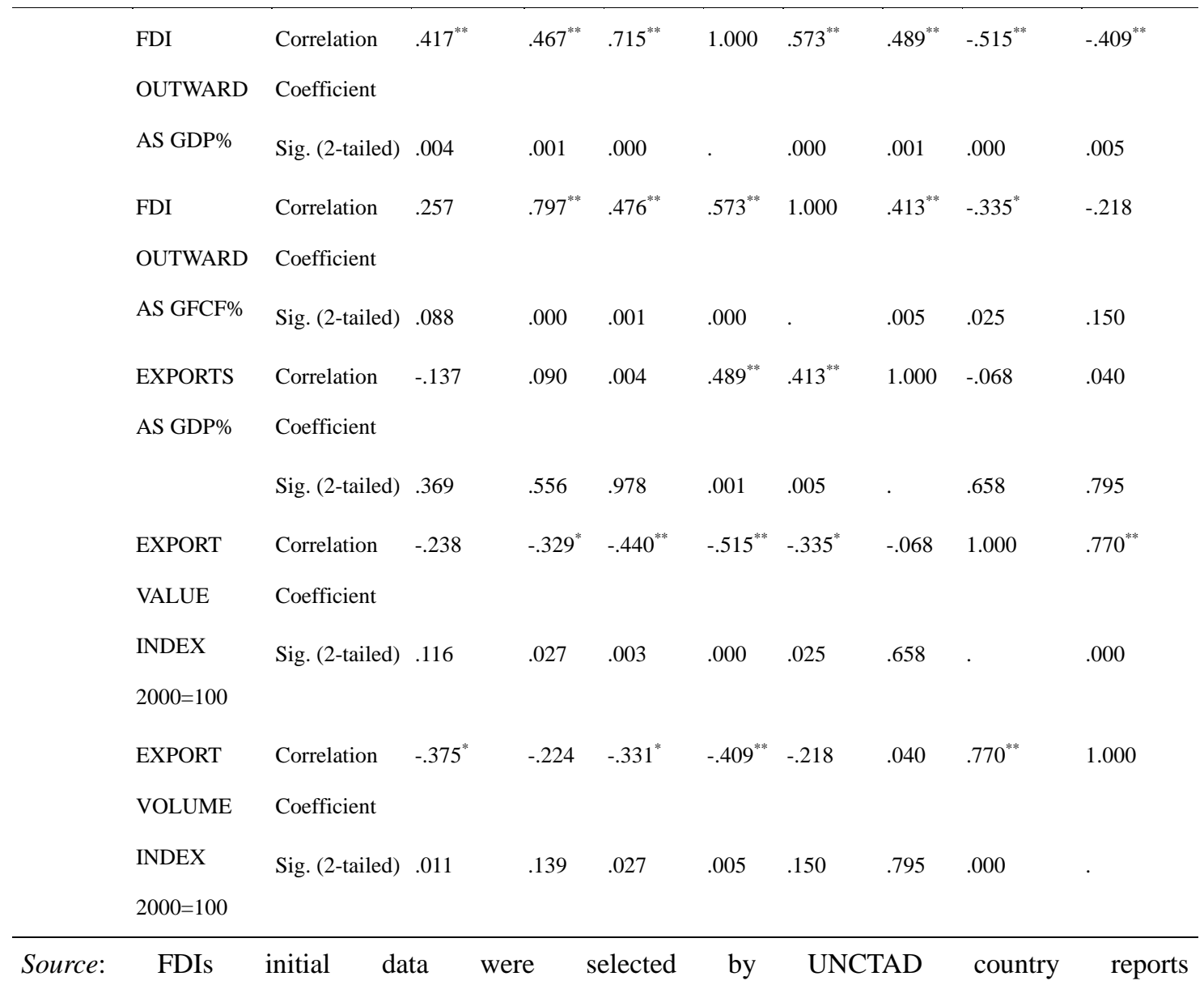

$<$ http://www.unctad.org/en/Pages/DIAE/World\%20Investment\%20Report/Country-Fact-Sheets.aspx>, and initial data on Exports were collected by the World Bank $<$ http://www.data.worldbank.org/indicator/TX.QTY.MRCH.XD.WD/countries>.

**. Correlation is significant at the 0.01 level (2-tailed).

*. Correlation is significant at the 0.05 level (2-tailed).

a. Listwise $\mathrm{N}=45$.

A linear regression analysis was performed in order to test if the variables of outward FDIs and exports were significant predictors of a country's success to transfer its own cultural product abroad given the others variables (see Table 4). The depended variable was the sum of book-titles by country of origin (authorship) which were found to be imported by the 52 country-groups of the study. This variable represents the numerical score of books exported and translated to the language of the importer country. The analysis showed that only two variables remained statistically significant over and above the other independent variables (see outward FDIs in mil. \$ $(\mathrm{p}=0.016)$ and outward FDIs stock in mil. \$ $(\mathrm{p}<0.001))$. The variables of outward FDIs as GDP\% and export volume index lose their significance. Given that the variable of outward FDIs stock in mil. \$ was referred to the time period of 1980-2012 it is eloquently concluded that enduring cross-border investments is the key factor that creates the 
environment for cultural spillovers. Indeed, FDIs stock amount and reading books of foreign authorship are thought to be reciprocally related to each other. As FDIs stock increases, the demand for books of foreign authorship increases, which in turn increases the amount of exported books.

Table 4. Results from Linear Regression Analysis with Dependent Variable the Sum of Book-Titles by Country of Origin

\begin{tabular}{|c|c|c|c|c|c|c|}
\hline \multicolumn{7}{|c|}{ Coefficients $^{\mathrm{a}}$} \\
\hline & & \multirow{2}{*}{\multicolumn{2}{|c|}{$\begin{array}{l}\text { Unstandardized } \\
\text { Coefficients }\end{array}$}} & \multirow{3}{*}{$\begin{array}{l}\text { Standardized } \\
\text { Coefficients } \\
\text { Beta }\end{array}$} & \multirow{4}{*}{$\begin{array}{l}- \\
.256\end{array}$} & \multirow{4}{*}{$\begin{array}{r}\text { Sig. } \\
.799\end{array}$} \\
\hline & & & & & & \\
\hline \multicolumn{2}{|c|}{ Model } & $\mathrm{B}$ & Std. Error & & & \\
\hline \multirow[t]{5}{*}{1} & (Constant) & 8.612 & 33.644 & & & \\
\hline & FDI OUTWARD_2012_MIL.\$ & -.002 & .001 & -.589 & -2.518 & .016 \\
\hline & FDI OUTWARD STOCK_2012_MIL.\$ & .000 & .000 & 1.347 & 5.584 & .000 \\
\hline & FDI OUTWARD AS GDP\%_2012 & -.666 & .348 & -.194 & -1.917 & .062 \\
\hline & EXPORT VOLUME INDEX 2000=100_2012 & -.005 & .137 & -.004 & -.035 & .972 \\
\hline
\end{tabular}

a. Dependent Variable: SUM_BOOK AUTHOR: the sum of book-titles collected abroad by country of origin.

Table 5. Model Summary

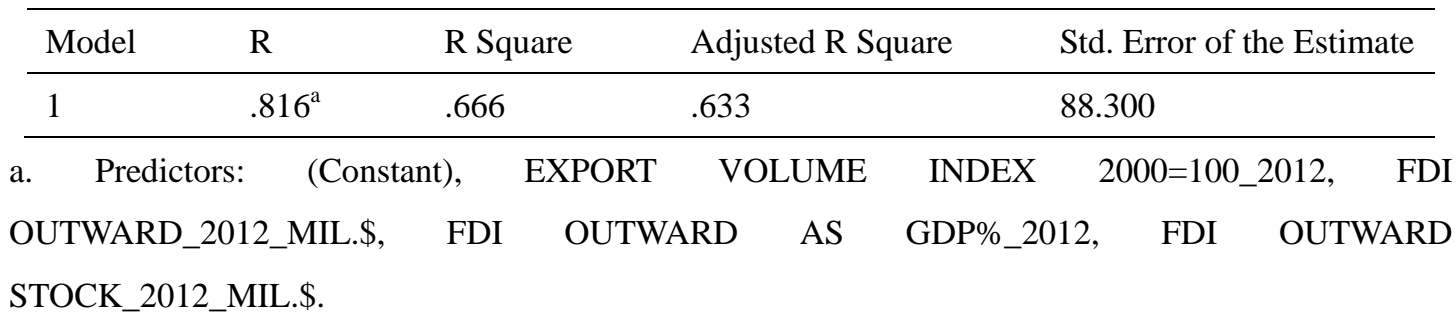

Table 6. ANOVA Results

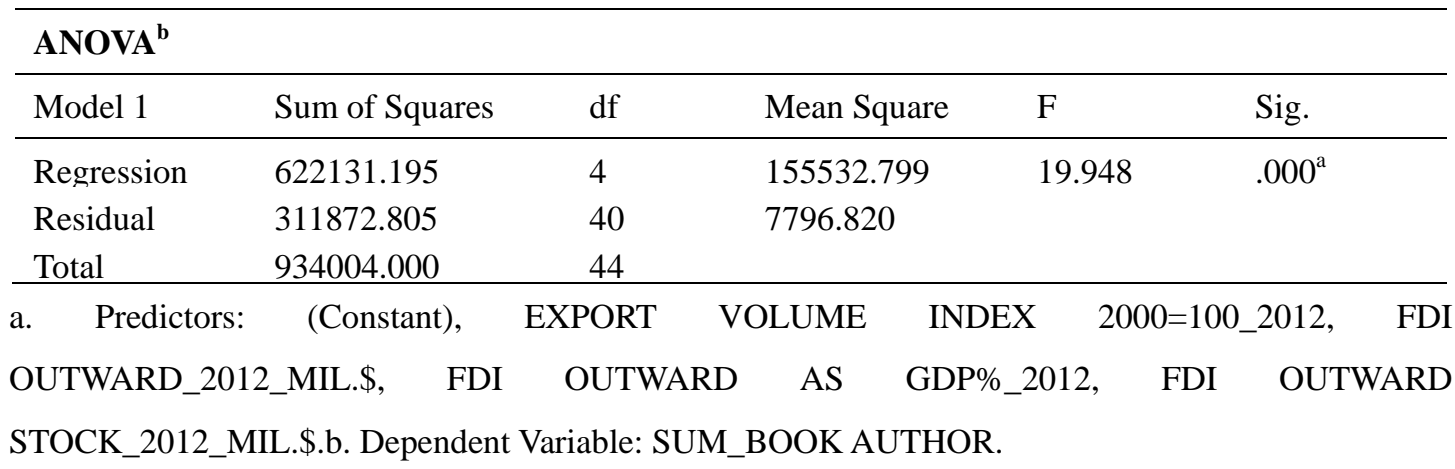




\section{Discussion}

Since 1605 where Francis Bacon was concerned about culture, a lot of attention was payed to the term. The issue was duly addressed for centuries but it was only in the 1990s that scientists reached to an adequate definition (Apte, 1994). The multiple usages and meanings of the term culture are attached not only to "conceptual or semantic" issues but also to "different political or ideological agendas" (Avruch, 1998). Systematic reviews about the concept of culture depict the magnitude of its applications to the scientific research (Spencer-Oatey, 2012). While much of the related academic work is employed by anthropologists and social scientists, lately the increased interest in culture has led to new approaches on economics, business strategy/management and policy making. In fact related theories emerged in the 1980s and thereafter were evolved to empirical studies and modelling, tied to specific contexts (Allaire \& Firsirotu, 1984; Ferraro, 1998; Hofstede, 1991, 2001; Dauber, Fink, \& Yolles, 2012; Guiso, Sapienza, \& Zingales, 2015; Maximini, 2015).

The concept of cultural products is attributable to the economic view of culture and involves cultural goods and services. Cultural products are subject of human creativity and are protected by intellectual property laws. It is argued that the cultural products integrate both commercial and cultural value which in some cases is priceless. Most of cultural products are or were produced for merchandise purposes. Their production is expressed by the term cultural industry which is introduced by T. Adorno and M. Horkheimer (1947) about seven decades ago. UNESCO acknowledged the value of cultural industries to the modern post-industrial knowledge-based economies in terms of growth, job creation and cultural issues. Therefore, UNESCO approaches the term as those industries that combine creation and commercialization via a production process. The creative output may be a good or a service that conforms to copyright norms (UNESCO, 2006). Cultural economics applies to the economic aspects of cultural products and provides economic analysis of cultural industries in the microeconomic level (for instance consumers' behavior analysis) and the macroeconomic level (for instance governmental policy analysis) (UNESCO, 2010). As the topic of cultural economy was introduced to the international economic relations, the aim of the present study was to investigate the interaction of cultural products with the cross-border trade (exports) and investments (FDIs). Findings could be valuable not only to the discipline of international economic relations but could also penetrate to the dynamic principles of culture as an interactive stream of economic development and diplomacy.

The impetus creativity in the world economy urged the national economies to classify and organize their cultural industries under the principles of competitiveness and innovation. The classifications vary between countries, nevertheless literature and publishing are acknowledged as the core cultural industries. Books are one sort of the final product of literature and publishing which are subjects of trade given that they merit of commercial value, low costs of reproduction and low costs of cross-border transactions.

Books are a great pool of knowledge not only due to their content but also on the statistics that provide regarding several variables. Reading books it reflects a trend of consuming behavior which is useful to 
marketing policies and sales promotion. Nevertheless, the analysis of differences in consuming behavior between groups of consumers unfolds a wider spectrum of knowledge that can be used by historians, macroeconomists, librarians, politicians, professors, artists, and social scientists. Literature review showed that not much was explored if the international trade and FDIs are affecting any of the specific cultural industries.

In this context the aim of the present study was to investigate if FDIs and exports affect cultural differences between cross-border partners. In other words it was assumed that reading preferences in a certain country are changing as the country imports goods and services by other countries and succeeds to attract FDIs. This demonstrates that the openness to the international economic relations leads to cultural bridging between the domestic and the foreign economy.

Data upon the book collections were collected by the LT on line library. All the LT countries attributed to languages of the research denote that the users read for pleasure. Most of the top 50 annotated books belong to fiction, classics and literature. It is noteworthy that only in the case of the Arabic site as the top author appears the World Health Organization.

Results denote a strong impact of many cultures in reading preferences given that each country group collects books originated by minimum 3 countries and maximum 19 countries. Data reveal that UK is the country with the major cultural influence in European readers. Asian, African and Chinese groups are also pegged to the British literature but lower rates are observed to the Yiddish, Tagalog (Philippine) Japanese, and Serbian groups.

Moreover, the Asian countries tend to be less affected by multiple cultures. In fact, the Muslim-related country groups were found to read foreign books by an average of eight different countries. The best performer in attracting book readers to those geographic areas was the US literature with an average market share of $40.5 \%$ of the foreign literature. In the China and Japan groups seven different countries were identified as having exported books to the Chinese and Japanese book markets. The best performer was USA which reached a market share of $47.4 \%$ and $44.0 \%$ of foreign literature respectively.

The three CIS country-groups have at minimum an impact of eight foreign countries and at maximum twelve (average 11 countries). The US literature represents in average the $41.2 \%$ of foreign books and the UK literature the $19.1 \%$.

Eurozone was represented by 13 country-groups and the impact of multiple cultures was by average attributed to 11 countries. The best performer was the UK literature and the second best the US literature. The average market share was $41.28 \%$ and $14.86 \%$ of foreign literature respectively.

UK and USA writers are on the top of the list sharing a common and valuable characteristic. Written in original language of "engilsh", results confirm previous research about the advantage of the language in international trade and foreign direct investments (Ghemar et al., 2005; Oh, Selmier, \& Lien, 2011; Selmier \& Oh, 2012, 2013).

Other macroeconomic data such as economic growth rate are irrelevant given that the countries with a 
high rate of development (BRICS—Brazil, Russia, China, India and S. Africa) had low rates of transferring their own book-culture abroad. In fact their performances reflect the $4^{\text {th }}, 8^{\text {th }}, 26^{\text {th }}, 28^{\text {th }}$, and the $31^{\text {st }}$ positions between 45 competitive countries. The first four ratings were gained by four countries of the Group of Eight (G8), i.e., the group of eight highly industrialized nations (see Table 2). The remaining four nations reached the $6^{\text {th }}, 7^{\text {th }}, 11^{\text {th }}$ and the $15^{\text {th }}$ positions. Concurrently these nations are great performers in exporting and investing abroad. This fact implied a relation of cross-border economic behavior and culture. Therefore the present paper empirically investigated FDIs and exports as the explaining variables of the phenomenon. Detailed results revealed that (i) the outward FDIs in millions of $\$(p=0.004)$, (ii) the stock of outward FDIs in millions of $\$(p<0.001)$, (iii) the outward FDIs as GDP percentage $(\mathrm{p}=0.004)$, and $(\mathrm{v})$ the export volume index $(\mathrm{p}=0.011)$ are statistical significant with the amount of the book titles traded abroad. No significance was found to (i) the outward FDIs as Gross Fixed Capital Formation (GFCF) percentage, (ii) the exports as GDP percentage, and (iii) the export value index. Regression analysis showed that the greater effect is attributed to the outward FDIs stock in mil. $\$(\mathrm{p}<0.001)$ which was referred to the time period of $1980-2012$. In other words, results showed a strong relation of what a country prefers to read and the volume of imports and finance that receives from abroad. This finding enriches previous research which showed that reading for pleasure leads to a better understanding of other cultures (Meek, 1991) and as a consequence it can be signified that FDIs, exports and book reading of foreign authorship are synergistic phenomena.

So far, literature had concluded that FDIs affects positively the host country by inducing managerial and technological knowledge spill-overs. This progressive status is beneficial to the international economic relations through the further up exports opportunities which lead to an extensive variety of products (Brenton, Di Mauro, \& Lücke, 1999). Existing theories explaining FDIs flows and economic transactions include language and cultural heritage as instruments that reduce transaction costs among the foreign and the investment-receiver (domestic) states. Kim et al. (2015) state that the more the domestic population is familiar to a certain language the greater is the likelihood of attracting investments by the particular FDI-sender state. In a similar manner, domestic Editing Houses can follow particular language authorship to reduce transaction costs. These costs reflect comprehension of contract terms, copyright obstacles, convenience or charges by the foreign to the domestic Editing House. Language facilitates an effective business communication of counterparts. The extensive use of English seems to operate as a powerful competitive advantage for UKs authors. In this context literacy in English data among countries could provide a supplementary explanation.

Further research should be practiced on Editing Houses and their motivations on paying copyright in order to translate a book of foreign authorship. Undoubtedly business criteria will be unfolded in order to gain profit. For certain, English is an international language, diffused all over the world making easy to find professional translators. Finally, book consumers such as in the UK and USA may be perceived more mature and a local success could be brought abroad. Supporting industries such as cinema and theater should be considered as variables that influence the diffusion of a book. 


\section{Conclusion}

Into the area of international business, failure to consider the cultural environment, can lead to costly ensnarement and dissociation of organizational goals. Most recent studies were focused on intangible variables, such as the existing cultural values, considered to be the driving force for business prosperity, under the assumption that cultural differences may hamper foreign entrepreneurs to operate effectively in the host country. Dealing with issues of cultural differences, this study has attempted to show how specific and tangible configurations of culture contribute to the improvement of international business operations. With particular emphasis on the functional areas of cultural economics, it was assumed that there is a reciprocal cultural relation between the investor and the host country. A sample of book readers and collectors by 52 country-groups retrieved by the digital library LibraryThing was investigated whether consumes books of foreign authorship. Foreigner-driven authorship was found to be catalogued by $81.2 \%$ of books. The success or failure of a country to transfer its own culture abroad as a literature product, i.e., books, was then statistically tested regarding on how effectively can practice cross-border outward FDIs and exports. Results showed that outward FDIs (expressed in mil. of \$, as a long-term stock, and as GDP\%) and exports (expressed as exports volume index) are culturally sensitive when there are long-term relationships and attuned to timing cross-border bilateral partnerships $(\mathrm{p}<0.05)$. Under the regression analysis outward FDIs in mil. \$ and outward stock FDIs in mil. \$ were strongly significant predictors of a country's success to transfer its own cultural product (books) abroad over and above the other variables ( $\mathrm{p}=0.16$ and $\mathrm{p}<0.001$ respectively). It is concluded that FDIs and exports are the vehicles of culture diffusion through foreign literature but enduring cross-border investments succeed to bridge the cultures of the economic partners. Therefore in the area of international business, the impact of the cultural environment can result bidirectional. In the bilateral economic relations cultural patterns interact and the host country gives a sort of cultural feedback to the investor country producing a cultural balance of the counterparts. In other words, cultural bridgework between the investor or the exporter and the host country was confirmed.

\section{References}

Adorno, T., \& Horkheimer, M. (1947). Dialektik der Aufklärung: Philosophische Fragmente. Amsterdam: Querido.

Alfaro, L., Chanda, A., Kalemli-Ozcan, S., \& Sayek, S. (2010). How Does Foreign Direct Investment Promote Economic Growth? Exploring the Effects of Financial Markets on Linkages. Journal of Development Economics, 91(2/March), 242-256.

Allaire, Y., \& Firsirotu, E. M. (1984). Theories of Organizational Culture. Organization Studies, 5(3), 193-226.

Apte, M. (1994). Language in sociocultural context. In R. E. Asher (Ed.), The Encyclopedia of Language and Linguistics (pp. 2000-2010). Oxford: Pergamon Press.

Astroff, R. (2001). Revitalizing a foreign literature collection. Collection Building, 20(1), 11-17. 
Avruch, K. (1998). Culture and Conflict Resolution. Washington, DC: Institute of Peace Press.

Bhardwaj, D., Arjun, J., \& Beamish, W. P. (2007). Host country cultural influences on foreign direct investment. Management International Review, 7(1), 29-50.

Brenton, P., Di Mauro, F., \& Lücke, M. (1999). Economic integration and FDI: An empirical analysis of foreign investment in the EU and in central and eastern Europe. Empirica, 26(2), 95-121.

Clark, C., \& Foster, A. (2005). Children's and young people's reading habits and preferences: The who, what, why, where and when. London: National Literacy Trust.

Clark, C., \& Rumbold, K. (2006). Reading for Pleasure A research overview. London: National Literacy Trust.

Dauber, D., Fink, G., \& Yolles, M. (2012). A Configuration Model of Organizational Culture. SAGE Open, 2(1), 1-16.

Denton, W. (2011). A Review of "Implementing FRBR in Libraries: Key Issues and Future Directions”. Cataloging \& Classification Quarterly, 49(1), 47-49.

DiNucci, D. (1999). Fragmented Future. Print, 53(4), 32, 221.

Ferraro, G. (1998). The Cultural Dimension of International Business (3rd ed.). New Jersey: Prentice Hall.

Ghemar, K., Wijnbergen, A., Iotsova, T., Sijses S., \& Skaskevitch Y. (2005). Study on Foreign Direct Investment (FDI) and Foreign Affiliate Trade (FAT) Between the EU and Canada. Brussels: Market Access Information and Analysis.

Guiso, L., Sapienza, P., \& Zingales, L. (2009). Cultural biases in economic exchange? Quarterly Journal of Economics, 124(3), 1095-1131.

Guiso, L., Sapienza, P., \& Zingales, L. (2015). The Value of Corporate Culture. Journal of Financial Economics, 117(1), 60-76.

Heuchemer, S., \& Sander, H. (2007). Do Cultural Affinities Influence International Trade? In Balimoune-Lutz, Nowak, \& Steagall (Hrsg.), Global Economy. Exploring New Capabilities (pp. 203-217). Warsaw: Elipsa.

Heymann, P., Koutrika, G., \& Garcia-Molina, H. (2008). Can social bookmarking improve web search (pp. 195-206)? Proceedings of the 2008 International Conference on Web Search and Data Mining, ACM.

Hofstede, G. (1991). Cultures and Organizations. Software of the Mind. London: McGraw-Hill.

Hofstede, G. (2001). Culture's Consequences. Comparing Values, Behaviors, Institutions, and Organizations across Nations (2nd ed.). London: Sage.

Hsiao, F. S. T., \& Hsiao, M. W. (2006). FDI, Exports, and Growth in East and Southeast Asia: Evidence from Time-Series and Panel Data Causality Analyses. Journal of Asian Economics, 17(6), 1082-1106.

Huberman, G. (2001). Familiarity breeds investment. Review of Financial Studies, 14(3), 659-680.

Hvass, A. (2008). Cataloguing with LibraryThing: As easy as 1,2,3! Library Hi Tech News, 25(10), 5-7. 
Jones, G. K., \& Teegen, H. J. (2001). Global R\&D Activity of U.S. MNCS: Does National Culture Affect Investment Decisions? Multinational Business Review, 9(2), 1-7.

Kim, M., Liu, A. H., Tuxhorn, K.-L., Brown, D. S., \& Leblang, D. (2015). Lingua mercatoria: Lunguage and foreign direct investment. International Studies Quarterly, 59(2), 330-343.

Kroski, E. (2007). Folksonomies and User-Based Tagging. In N. Courtney (Ed.), Library 2.0 and Beyond: Innovative Technologies ad Tomorrow's User (pp. 91-103). Westport, CT: Libraries Unlimited.

Loree, D. W., \& Guisinger, S. E. (1995). Policy and Non-Policy Determinants of U.S. Equity Foreign Direct Investment. Journal of International Business Studies, 26(2), 281-299.

Lu, J., Qiangbing, C., \& Yali, L. (2010). FDI and the change of the Chinese culture. International Journal of Social Economics, 37(2), 101-118.

Maximini, D. (2015). The Scrum Culture: Introducing agil methods for organizations. Berlin: Springer.

Meek, M. (1991). On Being Literate. London: Bodley Head.

Melissen, J. (2005). The New Public Diplomacy: Between Theory and Practice. In J. Melissen (Ed.), The new public diplomacy: Soft power in international relations. New York: Palgrave MacMillan.

NAEP, National Center for Education Statistics. (2013). A First Look: 2013 Mathematics and Reading: National Assessment of Educational Progress at Grades 4 and 8 (pp. 1-11). U.S. Department of Education.

O’Neill, J. (2007). LibraryThing: Cataloging for the (Social) Masses-While book lovers have been busy pooling data on their favorite books, they have also captured more than 16 million works and bonded with each other. Information Today, 24(8), 23-23.

O’Reilly, T. (2007). What Is Web 2.0: Design Patterns and Business Models for the Next Generation of Software. Communications \& Strategies, 1(65/March), 17-37.

OECD. (2002). Reading for change: Performance and engagement across countries. Results from PISA 2000. New York: Organisation for Economic Cooperation and Development.

Oh, C. H., Selmier W. T., \& Lien, D. (2011). International trade, foreign direct investment, and transaction costs in languages. Journal of Socio-Economics, 40(6), 732-735.

Robinson, M. (2008). Digital nature and digital nurture: Libraries, learning and the digital native. Library Management, 29(1/2), 67-76.

Sainsbury, M., \& Schagen, I. (2004). Attitudes to reading at ages nine and eleven. Journal of Research in Reading, 27(4), 373-386.

Selmier, W. T. II., \& Oh C. H. (2013). The Power of Major Trade Languages in Trade and Foreign Direct Investment. Review of International Political Economy, 20(3), 486-514.

Selmier, W. T. II., \& Oh, C. H. (2012). International business complexity and the internationalization of languages. Business Horizons, 55(2), 189-200.

Shenkar, O. (2001). Cultural Distance Revisited: Towards a More Rigorous Conceptualization and Measurement of Cultural Differences. Journal of International Business Studies, 32(3), 519-535. 
Spencer-Oatey, H. (2012). What is culture? A compilation of quotations. GlobalPAD Core Concepts. $\begin{array}{llll}\text { Retrieved } & \text { September } & \text { 4, 2015, from }\end{array}$ http://www2.warwick.ac.uk/fac/soc/al/globalpad/interculturalskills/

Spiteri, L. F. (2010). Incorporating Facets into Social Tagging Applications: An Analysis of Current Trends. Cataloging \& Classification Quarterly, 48(1), 94-109.

Tesar, L. L., \& Werner, I. M. (1995). Home Bias and High Turnover. Journal of International Money and Finance, 14(4), 467-492.

UNESCO. (2006). Understanding Creative Industries: Cultural statistics for public-policy making. Montreal: UNESCO.

UNESCO. (2010). Creative Economy: A feasible development option. Montreal: UNESCO.

Watson, A. (2008). Distributed Authority Control in the Age of Web 2.0: The Case of LibraryThing. Paper presented at the Questioning Authority Conference, University of Michigan School of Information.

Worrall, A. (2010). Supporting Community-Building in Digital Libraries: A Pilot Study of LibraryThing. Proceedings of the American Society for Information Science and Technology, 47(1), 1-3.

Xu, B. (2000). Multinational Enterprises, Technology Diffusion, and Host Country Productivity Growth. Journal of Development Economics, 62(2), 477-493. 